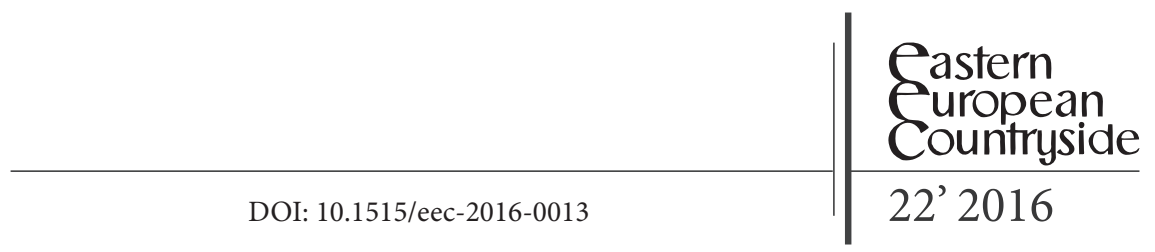

Wojciech Goszczyński

Institute of Sociology, Nicolaus Copernicus University

\title{
Bridging Food Studies
}

David Goodman, Melanie Dupuis, Michael Goodman, Alternative Food Networks: Knowledge, Practice and Politics, Rutledge, 2014, 308 pp.

The issue of the social importance of food seems to be gradually breaking through to the mainstream of the social sciences. This process began with agricultural sociology oriented towards Marxism, where food was analysed as one of the elements in a complicated puzzle describing relationships of authority, resource transition systems, agribusiness, and rural areas' sector policy development. On the other hand, anthropology, focussing on behaviours and consumers' mindset, which is often ignored in rural sociology, became also a very distinct source of inspiration. David Goodman, Melanie DuPuis and Michael Goodman attempt to fill this gap in their book referring to the Alternative Food Networks. This concept, developed by rural and agricultural sociologists, relates to new forms of social organisation, food production, and consumption. This concept is being constructed in opposition to industrial, mass agriculture, and includes various and slightly eclectic initiatives starting from direct sales, through box schemes and community-supported agriculture, to global certificates of ecological food and fair trade.

The authors in the reviewed publication focus on theoretical and empirical attempts to reconstruct the importance of alternative relationships binding producers and food consumers. This subject area is particularly 
important in the case of rural areas in Central and Eastern Europe. While analysing the situation of agriculture in those countries it is possible to find that it is subjected to three parallel and global processes. The first one is related to industrial integration of the agribusiness sector and results in increasing commoditisation, specialisation and homogenisation of agriculture and food production (Buttel 2006). By describing this phenomenon from a food studies perspective, we can talk about increasing the distance between the producer and the consumer, a price decrease, a product availability increase, and mass consumption development, based on the discounts and the supermarkets. The second dynamic of change in agriculture, the countryside and food is called post-productivism. It is related to the fall of agricultural importance, de-agriculturalisation, and the change in rural areas' functioning, urbanisation and putting the countryside in the backwaters (Marsden 2003). Food has two functions in this model. Every day it has to satisfy needs and not cost too much; however, on some special occasions it has to remind about childhood flavours and be based on a traditional understanding of high quality. The third dynamic observed in the countries of Central and Eastern Europe refers to the idea of rural area development; in the case of food it is based on attempts at localisation and implanting (ex. Bilewicz, Spiewak 2015). Those three interpermeating dynamics cause food production and consumption to appear to be a complicated combination. On the one hand, we have agritourism farms, rural communes or whole regions in which strategies in large part are based on local products and an attempt to sell them. Green markets and purchases made directly from a farmer are experiencing a renascence. Consumer initiatives were unknown earlier in this part of Europe, e.g. urban cooperatives or community-supported agriculture, where urban consumers play the main role. A paradox that authors of "Alternative Food Networks" capture (ex. in chapter 2) and to which they refer in their thesis time and time again is the large gap in simple initiatives, focussed on the producer, referring to tradition, and based on simple social relationships. On the other hand, we have elite initiatives where the customers rule, referring to a rusticity to a lesser extent, rather emphasising the political or aesthetic importance of food. This duality correlates interestingly with the studies on food. Thus, we have agricultural sociology which treats the consumer as an inactive receiver subjected to commodity fetishism. His desires, values, and mindset about the world are ignored in the analysis. On the other hand, consumption anthropologists seem not to observe a role and importance of the countryside 
and production, slightly naively approaching the role and importance of the alternative food networks.

An attempt to fill this gap can be found in the reviewed book. It has been divided into four main parts. In the first one, in three chapters, the authors try to build common theoretical frames, allowing to join together agriculture and consumption. This fragment of the publication consists of three chapters, introducing the conception of the alternative food networks (chapter 1), defining the reflexive localism concept (chapter 2), and considering the role of knowledge in bridging the studies on production and consumption (chapter 3). Part two refers to the alternative forms of food supply in Western Europe. Authors focus on agricultural re-localisation processes and mechanisms of the Common Agricultural Policy (chapter 4), problems of food quality social construction and who has an influence on it (chapter 5 ), and the assessment of change potential of the consumption paradigm and rural area development (chapter 6). Part three focuses on the description of an alternative in food in the United States: the cradle of social movements focussed on political, involved forms of food production and consumption. It is possible to find in the book the descriptions of sustainable and organic agricultural institutionalisation and industrialisation (chapter 7), the role and importance of a civic virtue and communication in alternative food networks' consolidation (chapter 8), and different mechanisms of knowledge construction concerning food and production (chapter 9). The last fragment of the reviewed publication refers to descriptions of alternative food networks' globalisation. Authors analyse the fair trade network transition processes - with particular consideration towards changing meanings (chapter 10), fair trade network organisation transitions (chapter 11), and globalisation of initiatives related to food (chapter 12). Due to this, we achieve crosssectional projection on issues of alternative forms of food implanted in the social sciences, as well as its production and consumption. Construction of the book is based, above all, on theoretical deliberations, analysis of other theses concentrating on food and agriculture, and analysis of existing data. The book does not include authorial field research. Rather, it has a handbook character, presenting the state of the discipline, the scope of research, and basic data.

Here the reader may ask a question: why the book of which an empirical part focuses on Western Europe and the United States appears in a magazine that concentrates on the countryside in Central and Eastern Europe. Three 
main reasons as to why every scientist interested in the food topic should read it can be indicated.

The first one has a theoretical character and relates to the state of the discipline. The problem for studies on food, agriculture and consumption is their lasting in consolidated intellectual traditions. Authors of the reviewed publication in chapter one prove that conceptual support of agricultural sociology causes the research to end with going outside the farm, and categories of agricultural sociology stop at a level of abstractional agribusiness-sector analyses and cannot handle the more subtle issues, e.g. influence of culture and social identities of both the farmers and the consumers. On the other hand, the anthropology of consumption and food focuses on intangible importance of products and consumer practices, ignoring their relationship with and influence on the rural areas, the role and importance of power, and global transition network construction. This causes the studies on food to be restricted by a language of particular subfields. Three authors of the reviewed publication propose a theoretical bridge over different traditions. For them the reflexivity concepts constitute the starting point - understood as a processual approach to locality and food, shared knowledge production - defined as a need to analyse the influences of different kinds of knowledge on discussed networks, and, lastly, the alterity - the acceptance of diversities and uniqueness of these alternative food networks. Authors of this publication treat food as a dynamic phenomenon exceeding static conceptual frames. An important message of the reviewed book says that the social importance of food is being shaped by the context in which the farmers, consumers, sellers, politicians, and persons involved in the network put it. In this regard, food itself is not as important as the process of its social construction and who, and in what manner, has an influence on it. It is very interesting theoretical operation after all, which is visible also in the case of food researchers in Central and Eastern Europe (Gorlach, Adamski 2010). For that reason, when researching food we do not examine only the simple resources which can contribute to the development of a given commune - we exceed treating food as a simple commodity distributed by the agribusiness networks. Focussing on the process secures the authors before one of the largest problems related to studies on food, i.e. enough naive, strongly positive valuation of all of its alternative forms. Such an unconditional positive approach is often seen in studies concerning the meaning and role of high-quality food in Central and Eastern Europe. In such types of studies, 
on the one hand, the locality itself is a sufficient indicator of the quality (ex. Jęmczyk 2015) and, on the other hand, elite and niche consumers' activity, ex. within consumer cooperatives, is treated as substantial innovation and a chance of positive social change (ex. Potkańska 2014: 58). This simplified view on food results also in practical activity - regions' development strategies are full of plans on how to use local products - simultaneously based on their easy understanding and traditional distribution methods. Instead of it, the authors of the reviewed book on many occasions emphasise that it is necessary to avoid such simplifying. They indicate threats related to the development of local food; they show consolidation of the gender stereotypes, racism, ethnical conflicts, and industrialisation as elements which can be related to alternative (local, organic, traditional) food. They emphasise that, depending on the context, it may be a chance or threat for the farmers, inhabitants of villages, and urban consumers. David Goodman, Melanie DuPuis and Michael Goodman in chapter two reject communitarianism - positioning values in rural or consumer communes, a simple regionalism indicating the dominating importance of local resources and the manner of handling problems, and, lastly, neoliberalism, emphasising the importance of global markets. The processual approach, referring to an idea of reflective localism, is supposed to be an alternative for food perception based on an idyll (also: Fonte 2013). According to the assumption by the book's authors, this approach does not favour any level, unit or institution. Locality is essential but as the space in which food is being constructed, and not as a goal itself. Authors of the "Alternative Food Networks", in an interesting manner, refer to modern humane geography, which, in a similar manner, approaches locality while treating it as some kind of natural frame that determines the place which becomes social, but without unambiguously positive or negative appraisal of a place itself (ex. Massey 2005). The reflective approach to food, presented in the whole discussed publication, means conditional acceptance of food re-localisation processes, but with simultaneous rejection of an optimistic vision that what is local is good. In other words, the proposed approach assumes that the alternative, local food should be treated as a phenomenon, binding different persons, institutions and policies, and having different, often contrary goals and interests. From the point of view of studies on food, agriculture, or even rural areas, it is a very interesting change, because it assumes a combination of optimism and idealism of local studies with a more realistic and slightly 
sceptical perspective of local and global interests and authority influence on the shape of the alternative food networks. According to the authors of the book, it has to allow analysing and shaping the alternative food networks so that they have no niche, elite character, but to let them have an influence on the whole production, processing and food supply system. From the point of view of Central and Eastern Europe, it is an interesting perspective. When observing the alternative food development it is actually possible to see two contrary dynamics. On the one hand, "festival" products appear, with local brands based on a simplified understanding of tradition and quality related to it, other shelves in supermarkets with food that simulates the regional food, or idyllic inns where locality ends with the reference to folkloric imaginations about the rusticity. On the other hand, the consumer cooperatives are being developed, and agriculture is supported by a society of network initiatives in the eateway type, where local consumers, derived from a new middle class, creative class or new urban movements, search for a high-quality product, not necessarily paying attention to a disproportion of power within the networks they create. In this regard, the reflective approach to food proposed in the reviewed publication seems to avoid those traps, encouraging the researchers and practitioners towards more careful analysis of contexts where both agriculture and food consumption are functioning.

The second substantial reason as to why it is worth reading the reviewed publication is related to the attempt to build bridges between the studies on production and food consumption analyses. Authors note a strong asymmetry in treating consumers' behaviours, as well as consumption and food anthropology achievements by rural and agricultural sociologists. It is difficult not to accept this argument. A review of literature on the subject and research shows that analysis of attitudes, values, and the influence of urban consumers is an unsurveyed area, besides not numerous exceptions (ex. Bilewicz, Śpiewak 2015). Stewart Lockie has even created a special concept, naming the consumers the invisible mouth, because they are treated only through their decisions concerning purchasing, who are important only for a moment: on shelves in a store or on the green market (Lockie 2002). Meanwhile, the anthropologists who are practically absent in the literature concerning rural and agricultural sociology (ex. Belasco 2008; Ashley 2004) indicate a deep-rooted importance of food in culture. It can be treated as a totem and is connected with the identity, body, sexuality, gender, social 
divisions, and civil cultural character. For sociologists, food is sparking from meanings which are together with production, buying, preparation and consumption processes.

It also relates to another, which was raised with the authors in chapter three and further empirical chapters that are the subject of binding the different knowledge systems. Relational hybridisation of the knowledge process is important for them. Behind this complicated term, the process of social food creation by different people and institutions operating at different levels is covered. Looking at a piece of local cold meat, we actually see the knowledge and skills of the producer, the farmer's behaviours, and the consumer's attitudes. We can also observe the influence of marketing knowledge, the impact of institutions regulating trade in foods, development policies, and sanitary control systems. In this piece of food the local knowledge (hidden, expert), a character of consumer culture, rural traditions, fashions, desires, demands and emotions are relying on each other. In this regard, the food is a knot, a black box which, after disarmament, can tell us something interesting about society in which we live (Hessanein 2003). In chapter three, Goodman, DuPuis and Goodman propose that it is possible to look inside this box using new conceptions. For example, in their thesis they refer to a theory of social practices gaining higher and higher popularity and today being developed by Theodor Schatzki. In a large simplification, it assumes that different actions, including eating, are focussed on a consistent beam ordered by values of different social practices (Schatzki 2002). In this regard, the consumer, by purchasing the local product at the green market, does not make only a simple, rational choice, but acts in consonance with some predefined social practice which determines how he should behave and what is good and healthy for him. Such an approach extends the meaning of consumption. The consumer involves himself in the alternative food networks not because he seeks an objective, high-quality product, but because social practice suggests what has high quality and what does not. If we assume such optics, then the analysis of food transitions or wider processes in the countryside, without taking into consideration external context, would be incomplete. To do this, they have to go outside the range of their narrow discipline.

Meanwhile, it seems that beyond non-numerous exceptions (ex. Gorlach, Adamski 2010), studies on food and practical actions using it in the development of the countryside in Central and Eastern Europe are still closed in frames of horizons designated by too simple and optimistic 
a view on alternative food. Local products on which the rural communes' development strategies are based are being built in isolation from consumers' needs, expectations and desires. They are constructed from simple blocks, which refer to a vision of a heavenly countryside, local symbols, and folklorism. This pushes the food and countryside to the peripheries, closing them in a capsule of not experienced time, while the authors of "Alternative Food Networks: knowledge, perspective and politics" make an attempt to break from this conceptual trap indicating the everyday meaning of alternative products and control mechanisms both at local and at global level. The whole empirical part of the reviewed book focuses on a description of how changes in agriculture, food production and also the countryside are correlated with changes of consumer behaviours, as well as policies and political institutions having an influence on the alternative food networks.

The third reason as to why it is worth reading the reviewed publication is connected with a description of development of social initiatives focussed upon alternative food. It is true that the empirical part is slightly chaotic and focuses, above all, on Western Europe and the United States, yet it allows the reader to follow the most important conditioning having an influence on the development of alternative food also in Central and Eastern Europe. For example, in chapter four the authors mention the influence of countercultural movements on the development of this type of network. Taking into consideration all differences, different traditions, history, and approaches to democracy, this type of movement starts to play a more and more important role also in the eastern part of the old continent. It is worth noting what is happening around new urban movements which try to implement new forms of relationships between the countryside and the city. Food cooperatives, agriculture supported by society, public kitchens, communal meal preparation, city gardens, and many more initiatives appear. Using the language of Richard Florida, a new, urban creative class (Florida 2002) starts to organise relationships between producers and consumers. The authors suggest that it is worth paying attention to a disproportion of power in such networks and the influence of elites from the middle class, influencing the rural areas which are being pushed into the vision of the city. Other clues, presented in "Alternative Food Networks", concern commercialisation and industrialisation of ecological agriculture, influences of Common Agricultural Policy mechanisms, constructing food quality, sustainable agricultural development, and, lastly, globalisation of the alternative food networks. The publication shows 
complexity and diversity of the processes occurring within production, processing, and food consumption. Goodman, DuPuis and Goodman suggest a critical approach which pays attention to the disproportion, relationships of authority, and unequal disproportion of resources with the constructive approach, which strives to transit the relationships between producers and consumers.

Coming to the end of the review, it is necessary to emphasise the importance of the discussed book. It is true that it will not allow understanding the initiatives concerning Central and Eastern Europe, but it provides theoretical inspirations. It equips the researcher with the language of description and analyses which allows multi-faceted food analysis. Authors construct bridges between different disciplines, description manners, and intellectual traditions. Additionally, in the publication, a review of the most important articles, concepts and research concerning agricultural, food and, partly, countryside analyses has been included. Of course, the thesis is not deprived of faults. Above all, it is very difficult to read. It requires the reader to have an advanced knowledge about concepts, theories and traditions used in social studies on food. It is intended for the inner circle of experts, but not for the broad, academical public. Simultaneously, the empirical chapter gives some insufficiency - slightly chaotic, general bases on the description of other research and analysis of existing data. Moreover, it seems that authors did not fully penetrate the conceptual fields which they had created. The consumers and producers have been technocratically described too rationally. In this regard, the empirical part, or actually the descriptive part, of the thesis consolidates the divisions which (in the theoretical part) were promised to be entombed. In spite of some inaccuracy, the reviewed book is a milestone in studies on food and is worth being recommended to researchers of processes of social constructing and meaning of food in Central and Eastern Europe.

\section{References}

Bilewicz, A., Śpiewak, R., 2015. Enclaves of Activism and Taste. Polish consumer cooperatives as alternative food networks. Socio.hu 3, Available at: http://www. socio.hu/uploads/files/2015en_food/bilewicz.pdf. 
Buttel, F., 2006. Sustaining the unsustainable: agro-food systems and environment in the modern world.

Gorlach, K., Adamski, T., 2010. One tradition, many recepices: social networks and local food production - the ocypek cheese case. In: Naming food after places: food relocation and knowledge dynamics in rural development, Authors: Maria Fonte, Apostolos G. Papadopoulos).

Florida, R., 2002. The Rise of the Creative Class. And how it's Transforming Work, Leisure and Everyday Life, Basic Books.

Fonte, M., 2013. Reflexive Localism: Toward a Theoretical Foundation of Integrative Food Politics. International Journal of Sociology of Agriculture and Food 20(3), Available at: http://www.ijsaf.org/contents/20-3/fonte/index.html.

Hassanein, N., 2013. Practicing food democracy: a pragmatic politics of transformation, Journal of Rural Studies 19.

Jęczmyk, A. 2015. Traditional and regional food products as part of the development of agritourism farms. In: Innovation of Rural Tourism and New Opportunities of Employment on Rural Areas Author: Wioletta Kamińska, PAN KPZG).

Lockie, S., 2002. The invisible mouth: mobilizng the consumer in food production consumption networks. Sociologia Ruralis 42.

Massey. D., 2005. For Space, Sage.

Marsden, T., 2003. The condition of Rural Sustainability. Royal van Gorcum (chapter published in Handbook of Rural Studies, Authors: Paul Cloke, Terry Marsden, Patrick Mooney, Sage).

Potkańska, D., 2013, Zmierzch epoki tradycyjnego konsumenta, czyli jak wspólne zakupy ekologicznej żywności kształtują tożsamość młodych Polaków. Odradzający się ruch żywieniowy kooperatyw spożywczych w Polsce - przykład Warszawy [Dawn of traditional consumerism: how community provisions shaped youth Poles identity - case study of Warsaw cooperative movements]. In: A. DrzałSierocka, W garnku kultury: Rozważania nad jedzeniem w przestrzeni społeczno kulturowej [Stiring culture and cuisine: rethinking food in socio-cultural space]. Schatzki, T., 2002., The site of the social. Pensylvania State University 